\title{
estudio sobre la determinación microquímica de la cal libre en el clínker del cemento portland
}

Uber die mikrochemische Ermittlung von frejem kalk jm Portlandzementklinker

Editorial, Silikattechnik, vol. $8, \mathrm{n}^{\circ} 2$, pág. 84 , febrero 1957

Generalmente se determina la cal libre en el clinker del cemento Portland, mediante el método de White. Depende de la reacción de $\mathrm{CaO}$ con fenol disuelto en nitrobenzol, mediante la cual se forman característicos cristales de fenolato cálcjłco. Toropow y Astreewa recomiendan para esta aplicación polvo reciente de clínker, para evitar la hidratación del CaO. W-W. Lapin llama la atención sobre ello, y experimentos de A. A. Mayer confirman que son también convenientes los ensayos sobre el $\mathrm{Ca}(\mathrm{OH}) \mathrm{g}$. La forma de los cristales de fenoiato cálcico dependen de cómo se realice la reacción de los reactivos con $\mathrm{CaO}$ o con $\mathrm{Ca}(\mathrm{OH})_{2}$. En el caso de $\mathrm{CaO}$ se forman finas y delgadas agujas de fenolato muy aglomeradas. Para la reacción con $\mathrm{Ca}(\mathrm{OH})_{2}$ se torman relativamente grandes cristales de fenolato bien diferenciados de agujas prismáticas. Debido a esta diferencia se comprueba de qué forma viene la cal libre. 